Meta

Journal des traducteurs

Translators' Journal

\title{
La métaréflexion de la traductologie brésilienne dans TTR et META : 1990-2012
}

\section{Raúl Ernesto Colón Rodríguez}

Volume 60, numéro 2, août 2015

$60^{\mathrm{e}}$ anniversaire. Les horizons de la traduction : retour vers le futur $60^{\text {th }}$ Anniversary. Translation's Horizons: Back to the Future

60mo aniversario. Los horizontes de la traducción: regreso al futuro

URI : https://id.erudit.org/iderudit/1032873ar

DOI : https://doi.org/10.7202/1032873ar

Aller au sommaire du numéro

Éditeur(s)

Les Presses de l’Université de Montréal

ISSN

0026-0452 (imprimé)

1492-1421 (numérique)

Découvrir la revue

Citer ce document

Colón Rodríguez, R. E. (2015). La métaréflexion de la traductologie brésilienne dans TTR et META : 1990-2012. Meta, 60(2), 322-322.

https://doi.org/10.7202/1032873ar d'utilisation que vous pouvez consulter en ligne. 


\title{
La métaréflexion de la traductologie brésilienne dans TTR et META: 1990-2012
}

\author{
Raúl Ernesto Colón Rodríguez \\ Université d'Ottawa, Ottawa, Canada \\ rcolo036@uottawa.ca
}

La traductologie brésilienne a parcouru un long chemin, de ses débuts jusqu'à nos jours. Des textes fondateurs d'Haroldo et Augusto de Campos à aujourd'hui, les traductologues brésiliens ont acquis une reconnaissance internationale soutenue. Depuis le Canada, la traductologie produite au Brésil est observée avec beaucoup d'intérêt. C'est peut-être la raison principale pour laquelle dès 1990, dans les deux plus importantes revues canadiennes, des auteurs brésiliens ont occupé un espace de choix. Dans notre communication, nous analyserons les réflexions que les traductologues et les traducteurs brésiliens dans les deux revues mentionnées ont faites sur eux-mêmes et leur travail, et sur l'évolution de la discipline au Brésil. Ces textes nous montrent l'avancement des études de la traduction au Brésil, à travers la métaréflexion de leurs propres agents et ils suggèrent également qu'autant les professionnels de la traduction que les chercheurs de notre discipline dans les deux pays, ont préparé le chemin d'une vaste collaboration académique dans les Amériques, où écouter et lire la voix de l'Autre est une priorité.

Raúl Ernesto Colón Rodríguez est doctorant en traductologie et professeur à temps partiel à I'Université d'Ottawa. II a travaillé en traduction éditoriale et cinématographique au Canada. II a publié dans TTR, Meta, HISTAL, Glendon Selected Proceedings 2013, K1N et Circuit (Canada) ; Mutatis Mutandis en Colombie, en Espagne et en Pologne. II s'intéresse aux liens entre traduction et idéologies et entre traduction, exil et migrations. 